\title{
NICOLAE-ALEXANDRU VIRASTAU, Jean Thenaud et François Rabelais
}

Filippo Fassina

\section{(2) OpenEdition}

\section{Journals}

\section{Edizione digitale}

URL: https://journals.openedition.org/studifrancesi/31498

DOI: 10.4000/studifrancesi.31498

ISSN: 2421-5856

\section{Editore}

Rosenberg \& Sellier

\section{Edizione cartacea}

Data di pubblicazione: 1 août 2020

Paginazione: 388

ISSN: 0039-2944

\section{Notizia bibliografica digitale}

Filippo Fassina, «NICOLAE-ALEXANDru VIRAStau, Jean Thenaud et François Rabelais», Studi Francesi [Online], 191 (LXIV | II) | 2020, online dal 01 septembre 2020, consultato il 18 septembre 2021. URL: http:// journals.openedition.org/studifrancesi/31498 ; DOI: https://doi.org/10.4000/studifrancesi.31498

Questo documento è stato generato automaticamente il 18 septembre 2021.

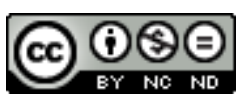

Studi Francesi è distribuita con Licenza Creative Commons Attribuzione - Non commerciale - Non opere derivate 4.0 Internazionale. 


\title{
NICOLAE-ALEXANDRU VIRASTAU, Jean Thenaud et François Rabelais
}

\author{
Filippo Fassina
}

\section{NOTIZIA}

NICOLAE-ALEXANDRU VIRASTAU, Jean Thenaud et François Rabelais, "Bibliothèque

d'Humanisme et Renaissance”, LXXXI-2, 2019, pp. 345-357.

1 Il presente studio ha come finalità quella di far luce sul rapporto fra Rabelais e Jean Thenaud, dottore in teologia, abate, astrologo ed esperto di spiritualità mistica e di cabala cristiana. Infatti, nel Gargantua, Rabelais fa alcuni riferimenti a Thenaud e, in particolare, al Voyage Itineraire, l'unica opera pubblicata in vita dal teologo. La critica tende a identificare nel personaggio rabelaisiano di Frère Jan des Entommeures una rappresentazione proprio di Jean Thenaud, mentre l'A. tenta di dimostrare la tesi diametralmente opposta, secondo la quale non vi sarebbe alcun legame fra i due. In primo luogo, Entommeures è benedettino mentre Thenaud è francescano; inoltre, il personaggio di Rabelais rappresenta la caricatura di un monaco, in quanto tenta continuamente di contraddire le regole della vita monastica, dimostrando un'ostilità per questo mondo che è tipico dell'ideologia di Rabelais. Al contrario, Thenaud riserva un ruolo centrale al monachesimo nelle sue opere. Altro punto di contatto rilevato dalla critica sarebbe la somiglianza fra lo pseudonimo di Rabelais (Nasier) e il nome dei uno dei personaggi inventati da Thenaud, il misterioso Nazaire. Tuttavia l'A. sottolinea come non vi sia alcun collegamento fra questi nomi, in quanto lo pseudonimo rabelaisiano sarebbe un riferimento alla grandezza del suo naso. Anche un problema di datazione dei testi sembrerebbe rigettare l'ipotesi di un riferimento diretto di Rabelais a Thenaud. In realtà l'accostamento fra i due autori sembrerebbe essere dovuto piuttosto all'influenza di Erasmo su entrambi i letterati francesi. Infatti, poiché Thenaud ha composto il primo adattamento francese dell'Éloge de la folie, in cui vengono moderatamente criticati gli ordini religiosi, alcuni critici hanno dedotto un rapporto 
diretto fra l'antimonachesimo di Rabelais e l'opera di Thenaud, ipotesi che sembra non essere plausibile sulla base dei dati forniti in questo studio. 